\title{
TESTEMUNHO E RESPONSABILIDADE NA CENA CONTEMPORÂNEA
}

\author{
WITNESSING AND RESPONSIBILITY IN CONTEMPORARY \\ PERFORMANCE
}

TESTIGO Y RESPONSABILIDAD EN LA ESCENA CONTEMPORÁNEA

Alessandra Montagner

Alessandra Montagner Doutoranda do Programa de

Pós-Graduação em Artes da Cena do Instituto de Artes da Universidade Estadual de Campinas e bolsista FAPESP. Diretora, atriz e pesquisadora da problemática do testemunho e da percepção do choque na cena contemporânea. 


\section{Resumo}

Este artigo reflete sobre a problemática do testemunho e da responsabilidade na recepção da cena contemporânea. São utilizados a experiência receptiva pessoal da autora e o depoimento de outra espectadora, sobre sua experiência da mesma obra, como meio para a viabilização dessa reflexão.

Palavras-chave: Espectador, Participação, Testemunho, Responsabilidade, Alteridade.

\section{Abstract}

This article reflects on the problematics of witnessing and responsibility in the reception of contemporary performance. A personal receptive experience of the author is used, as well as the testimony of another spectator, on her experience with the same piece, as a means to enable this reflexion.

Keywords: Spectator, Participation, Witnessing, Responsibility, Alterity.

\section{Resumen}

Este artículo hace una reflexión acerca de la problemática del testigo y de la responsabilidad en la recepción de la escena contemporánea. Se emplean la experiencia receptiva personal de la autora y el testimonio de otra espectadora, sobre su experiencia de la misma obra, como medios que van a permitir esta reflexión.

Palabras clave: Espectador, Participación, Testigo, Responsabilidad, Alteridad.

Em algum dia tardio de julho de 2012, no Bonnie Bird Theatre, Laban (Londres), Maciej Kuźmiński - bailarino, coreógrafo e educador polonês apresentava a obra Room $40^{1}$, da qual é coreógrafo. A coreografia desta obra de dança demanda grande esforço físico dos bailarinos, com sequências que priorizam a exploração do nível baixo (chão) e que repetidamente fazem uso da postura da "prancha", uma das posturas do yoga - na qual o corpo

1. Para mais informações sobre Room 40 , consulte o site do coreógrafo: http://maciejkuzminski.com/portfolio/room-40/. 
é amparado por quatro apoios, pelas mãos e pés, sem o uso dos joelhos. Naquele dia, o espetáculo começava com essa postura sendo sustentada por um grupo de bailarinos por vários minutos, sendo que a mesma recorria frequentemente durante a progressão da coreografia. Em determinado momento, uma das bailarinas iniciou um solo belíssimo, no qual, nua e acompanhada de uma mangueira que pendia do teto, dançava com a água que se acumulava na extensão do piso do palco. Seguindo o padrão desenvolvido pela coreografia, todo o solo se concentrava sobre o mesmo trabalho de chão, até o momento no qual a solista assumiu a postura da prancha e nela permaneceu. Algum tempo inexato se passou, no qual a bailarina manteve a mesma posição enquanto a plateia observava sua ação. Então, as luzes do auditório foram acesas e as do palco apagadas, e a música, que acompanhava o solo foi interrompida dando lugar aos sons que a bailarina emitia para manter-se naquela posição (naquele momento era possível ouvir seus gemidos), mas nós na audiência permanecíamos onde estávamos, imóveis em nossos assentos, assistindo ao esforço visível e audível da bailarina. Todos se mantiveram inertes, teoricamente, desinformados sobre o final do espetáculo, tensos com a indecisão diante do que fazer, até o momento em que um de nós, espectadores, se levantou, caminhou por um dos lados do auditório, e deixou o teatro. Aquela foi a atitude inaugural para que todos procedêssemos da mesma maneira, não havia mais desculpas, não poderia haver mais dúvida: deveríamos partir e acabar com aquele espetáculo, pois nossa permanência, ou recusa em partir, era decisiva para o prolongamento ou extinção daquela situação.

Em depoimento, a primeira espectadora a deixar o auditório, aquela que fundou a partida da audiência, relatou:

The piece was very physically demanding on the dancers. The entire opening section began with them in a plank position that they held for an exceedingly long time. (Note: it is rare for a beginner to even be able to hold it for 30 seconds) I think they were in it for nearly 5 minutes, or even longer. They had started to shake from the strain before they finally slowly released to the floor and the movement piece started.

There was a lot of floor work and again, very physically demanding. The 'lead' female dancer had a solo that finished off the piece where she 
rolled around quite frantically for a period of time. She was nude, and in water that was streaming down from a tube suspended from the rafters.

At the end of her solo, she again resumed the plank position and held it. The music which had been VERY strong and powerful opera music had finished by this time.

The audience hadn't moved, nor responded by applause or other outward sign.

After she had been in the position for a while, I could see she was exhausted and again, struggling to stay in that position.

I felt that we as the audience were ultimately responsible for how long she stayed in that position. By our NOT doing anything, she stayed where she was. It was uncomfortable to watch and feel as if somehow I was the one making her stay there by my NOT applauding or understanding the piece was finished.

So, I chose to leave the auditorium, if nothing else, so we could relieve her of the strain she was in.

I am aware the choreographer is the one who choreographed the piece and she as the performer agreed to do it. However, in that final moment, I feel it was up to us as to how long she had to stay there. I had had enough, and I had had enough of watching her struggle. So I left. ${ }^{2}$

Naquele dia, após todos termos saído do auditório e, como consequência, liberado a bailarina da posição em que ela se encontrava, a situação era estranha, desconfortável, embaraçosa. Claramente algo havia acontecido e se instaurado naquele espaço do teatro e da sua caixa preta, algo que demandava não apenas um posicionamento, mas, precisamente, uma tomada de ação por parte dos espectadores que compunham aquele evento. Uma situação se instaurou por meio de uma proposição, cruel (?) e provocadora, proposta a nós, espectadores: após termos fruído aquela experiência e consumido em segurança aquela obra, fomos introduzidos à responsabilidade de tê-lo feito e incumbidos de dar fim aquele espetáculo de dança e dor. Cada um

2. Depoimento concedido através de e-mail pessoal, em 2 de setembro de 2013. Todas as ênfases foram dadas pela depoente. 
de nós tinha que fazer uma escolha que fatalmente se constituiria enquanto atitude política diante daquela situação, daquela performance: poderíamos encerrar aquele evento com a nossa partida, ou persistir para testemunhar ainda mais esforço e aflição, ou o fracasso da bailarina. Afinal, como coloca Diana Taylor (apud STODDARD, 2009, p. 2), "looking is always an intervention, whether we like it, or accept it, or not. Not intervening, turning away, is its own form of intervention [...] Our choice is how, not whether, to participate". E assim participamos, fomos contemplados com o poder da decisão, pela nossa própria presença enquanto espectadores, sobre quanto a obra ainda deveria durar e quanto a bailarina ainda deveria persistir. Por não podermos escapar da atividade participativa - já que nossa presença naquele auditório implicava uma ação -, fomos, portanto, colocados na posição de testemunhas que atuam sobre o ocorrido ao mesmo tempo que são delatadas enquanto o fazem. Presenciávamos o ocorrido e éramos também, inevitavelmente, responsáveis por ele, pelo poder da nossa (in)ação. Mas quais as reais dimensões dessa participação e da responsabilidade que ela implica? Como o espectador se constitui no responsável pelas obras que escolhe testemunhar, e atitudes que adota na direção dessas?

O espectador se encontra, com frequência, no centro de muitas concepções artísticas na contemporaneidade. No que tange a cena contemporânea, diferentes estéticas da cena parecem ser propostas com o intuito de instaurarem experiências que se manifestem enquanto forças potenciais, capazes de problematizar, pela radicalidade da sua performatividade, muitas relações que permeiam o evento performativo, bem como a posição ontológica do espectador: enquanto aquele que recebe, que consome, que aprecia, vê e ouve a partir de certa distância, de uma posição removida da ação; aquele que contempla sem agir. Como já mencionado, a figura e o papel do espectador da cena têm sido constantemente desafiados por estratégias capazes de direcionar a experiência receptiva para direções liminares e ambivalentes, "fundadas por qualidades expressivas não descritivas, não explicativas, que não se valem de códigos já existentes" (BONFITTO, 2013, p. 98), por performances, ou cenas, que já não se preocupam mais em explicar nada, e sim em instaurar um processo em que diferentes dimensões das relações da cena são desafiadas. Dentre essas estratégias, saliento a questão da participação, 
afinal participar não é a função primeiramente atribuída ao espectador. Ela, na verdade, se constitui enquanto oposição a uma das premissas daquilo que Jacques Rancière (2009, p. 2) chama de o "paradoxo do espectador": no qual ser espectador configuraria o contrário de conhecer e de agir, embora não exista "teatro sem espectador". Esse paradoxo comunica o confinamento que a figura do espectador sofre quando abordada enquanto papel alienado e não emancipado, que, embora seja necessário ao evento teatral, perpetua o desempoderamento do indivíduo espectador perante a hierarquia teatral. Assim, a atividade participativa se enquadra e manifesta pela mera presença, pelo simples presenciar, do espectador de um evento performativo, para além da limitação do binarismo atividade vs. passividade, e é identificada enquanto forma de empoderamento e emancipação essencialmente constituinte do ato do espectador emancipado.

A participação foi explorada de diferentes formas ao longo da história das artes performativas, gerando alterações nas formas de apreciação da cena pelo espectador. Essas modificações em prol da participação espectatorial aliaram-se, com frequência, ao combate ao que era entendido enquanto passividade e/ou alienação do ato do espectador. A abordagem, daqueles que Rancière chama de os "reformadores do teatro", visava combater uma ideia específica atrelada à contemplação: abordada como oposição à ação dentro das premissas do espetáculo defendidas por Guy Debord em Sociedade do espetáculo (2003). A contemplação pela perspectiva desse autor compreende a noção da nocividade da atividade contemplativa inserida no espetáculo do capital, que promove a separação como regra e essência do espetáculo, em que a "alienação do espectador", enquadrada pela sua atitude de consumidor, dá-se pela alegação de que "quanto mais ele contempla, menos vive" (DEBORD, 2003, p. 25-26). O autor, portanto, contrapõe e distingue a atividade contemplativa da possibilidade de intervenção no mundo. É importante salientar que a reação de Debord à contemplação foi enquadrada por um momento histórico que reagia à apropriação do espetáculo, e da experiência estética, pelo mercado para o encorajamento do consumo. Assim, promover a participação enquanto polaridade contrastante à contemplação era uma forma de "reumanizar uma sociedade alienada e fragmentada pela produção capitalista" (BISHOP, 2009, p. 11). A utopia da participação nesse 
contexto era, portanto, um instrumento de emancipação do indivíduo para que não houvessem mais espectadores, e para que todos se tornassem agentes ativos na construção de um mundo igualitário. No entanto, diante da nossa atual conjuntura, em que inevitavelmente fomos engolidos e inundados pelo universo do consumo e pela espetacularização da sociedade, parece menos produtivo, e até limitador, pensar a problemática e o fenômeno da participação por essa via excludente e dualística - atividade vs. passividade, contemplação vs. participação - do que fomentar os espaços liminares presentes no continuum que compõe cada uma dessas questões, ou seja, as ambivalências presentes na atitude participativa do espectador.

Como consequência desse ideal de transformação do indivíduo pela arte, e da emancipação do espectador pela atividade estética, estratégias de participação têm sido aplicadas desde as vanguardas históricas até o experimentalismo das artes performativas da cena contemporânea, promovendo experiências que muitas vezes transformam o espectador em performer da ação. É importante apontar que tanto a ideia de performance e de ação nesse contexto são partes de um continuum de tensões e manifestações, em que agir e performar não se exprimem necessariamente de forma reconhecível, mas integram outros níveis de manifestação. Embora técnicas participativas tenham sido amplamente incorporadas pelas culturas contemporâneas no que tange as estratégias de participação nos reality shows (referentes ao participante direto ou votante) e das redes sociais e mídias digitais (BISHOP, 2012, p. 30), onde postagens constituem intervenções, a participação enquadrada pelo evento performativo tem sua força intensificada pelo potencial do encontro que compõe esse evento: pela coexistência de corpos atuantes e/ou receptivos que constituem e determinam o evento enquanto acontecimento social.

A atividade espectatorial se modificou consideravelmente no decorrer dos últimos séculos, sendo que uma "inversão da olhadela" subverteu a lógica da relação espectador vs. obra: a recepção contemplativa, na qual o espectador é abduzido pelo universo da obra, foi substituída por uma recepção na qual a obra inflige o espectador, se impõe enquanto presença por vezes inapreensível e violenta, tornando difícil estabelecer o significado daquilo que está sendo vivenciado (DESGRANDES, 2011). Por essa perspectiva, o es- 
pectador não se encontraria mais subjugado à obra e sua força, mas sentiria a sua presença enquanto corporeidade, que impõe e desvela o processo receptivo como local, e protagonista, do evento performativo. A obra em si aconteceria pela experiência particular de cada espectador, sendo enquadrada pelas experiências sensoriais deles e expressa pela qualidade da presença e atitude diante daquilo que é visto. Especificamente no caso das artes performativas, na cena contemporânea experimental, aquilo que é apresentado enquanto cena - quando determinados corpos atuantes se colocam em ação e/ou performance diante da apreciação, também atuante, da audiência - já não representaria mais uma ficção que transportaria os espectadores para o universo específico de uma peça, mas instauraria uma força performativa e afetiva capaz de intensificar radicalmente a própria presença do espectador. Nesse processo, o público se tornaria espectador de suas próprias ações e reações diante da cena veiculada. Como consequência, a audiência se "veria transformada não em espectadores de um espetáculo, mas em testemunhas de um evento". (ETCHELLS, 1999, p. 49)

Testemunhar é uma ação que traz consigo a participação em uma situação que ocorre, ao mesmo tempo, de forma distanciada e comprometida. A testemunha presencia algo que não necessariamente está diretamente implicada, mas pelo seu próprio ato de presenciar, estar presente diante de um ocorrido, ela se encontra comprometida e relacionada com o que foi testemunhado. Existem, obviamente, diferentes formas de testemunho: aquele que testemunha um acidente de trânsito muito provavelmente não pode evitá-lo; aquele que assiste a uma briga física entre duas pessoas nem sempre pode apartá-la, mas pode ser questionado quanto a moral da sua ação ou omissão diante da situação. E o que aconteceria com aquele que testemunha transgressões veiculadas pela cena, violações dos limites e direitos daqueles envolvidos no evento? Em Towards a phenomenology of the witness to pain (2009), Stoddard aborda o que ela chama de "testemunho estético", ou seja, o testemunho da "performance da dor", ou espetáculo da dor. Ela sugere que o termo "testemunha" engloba diferentes aspectos do ato de testemunhar. Entre eles teríamos a perspectiva da testemunha ocular, que atesta judicialmente algo visto, bem como a situação daquela que vivencia um fenômeno na irrupção do seu acontecimento, que reside em um corpo 
que se configura enquanto prova de um vivido atestado através da sua própria presença (STODDARD, 2009, p. 3), pelo fato de algo ter acontecido na sua presença. A autora prossegue sua análise pela dissecação do termo "to bear witness", que em português seria traduzido como "dar testemunho"; ou seja, atuar enquanto prova através do testemunho de algo presenciado/vivido. No entanto, uma das traduções do verbo "to bear" é também "suportar", o que parece um ponto interessante de ser considerado neste ensaio, pois suportar pode trazer consigo tanto a conotação de dar suporte ou apoio, quanto o ato de permanência diante de algo desconfortável - suportar algo. Nesse sentido, no que Stoddard classifica como a "performance da dor", to bear witness, quando traduzido para o português dentro do contexto dessa abordagem da noção de performance, também traria consigo a permanência e presença da testemunha diante da dor do outro: o suportar pela sua presença a espetacularização da dor do outro. Em que medida, portanto, a testemunha estética participa e fundamenta as violações da cena? Quão responsáveis éramos nós, os espectadores de Room 40, pelo sofrimento daquela solista?

Por essa perspectiva da recepção enquanto testemunho, não existe testemunho sem participação: essa é uma prerrogativa que deve ser aceita e transportada para a posição que adotamos diante da cena que suportamos, apoiamos, produzimos e consumimos. Como já expresso, a testemunha está envolvida na ação ou evento testemunhado e atua sobre ele, seja pela sua intervenção direta, seja pela sua omissão. Portanto, a partir dessa lógica, o espectador feito testemunhador não se classifica como um inatuante, ele atua independente da (in)ação adotada, e como tal é responsável pela sua postura frente aquilo que, diante dele, é veiculado enquanto arte. Com a emancipação e possibilidade de intervenção, ofertadas pela atividade participativa, vem a responsabilidade pelas ações adotadas diante do convívio proposto pela cena. Afinal, quais os limites da cena? O que ela pode retratar, presentar e instigar? Até que ponto a cena pode ousar questionar visões e padrões estabelecidos e contratos firmados? Sobre quais relações de trabalho e convívio a cena tem a licença de atuar? O que cabe ao espectador e qual seria a ética da sua presença e participação no evento, diante do evento, do performer e dos outros espectadores? 
Em Room 40, a situação delineada pela obra promove uma total desestabilização do convívio entre performer e espectadores e fomenta um território ambivalente no qual não existe clareza ou asserção da ação a ser tomada. "Ambivalence is about these moments of self-recognition but also about the internal processes of doubt, anxiety, reflection and consideration individual spectators go through in their attempts to make sense of, or to respond to a work" (GREHAN, 2009, p. 23). Portanto, a situação se estabelece como local de ambivalência, bem como fomento de tensões perante a ação a ser tomada como reação a permanência e sofrimento da bailarina. Enquanto espectadora desta obra, no momento onde uma ação era requerida - permanecer ou partir - foi difícil me mover em qualquer direção, entender o que deveria ser feito diante daquela situação. Nesse momento, o testemunho da cena, e deste trabalho, se intensifica e direciona para o desvelamento da responsabilidade do indivíduo perante o outro, questionando, portanto, uma ética de convívio enquadrada, aqui, pela relação performer vs. espectador.

Em Theatre \& ethics (2009), Nicholas Ridout faz uma dissecação da noção de ética aplicada aos diferentes momentos históricos da prática teatral, vista por ele enquanto "prática ética" capaz de fomentar diferentes perspectivas sobre "como agir". O teatro é aqui entendido de forma ampla, e o argumento do autor é utilizado pela perspectiva da noção de cena enquanto prática expandida. Esse "como agir" estaria, segundo esse autor, no contexto contemporâneo, centrado sobre o outro, como concebido pela ética da alteridade de Emmanuel Levinas. Logo, Ridout enfatiza que no contexto da contemporaneidade e, portanto, da cena contemporânea, pela utilização do argumento da ética de Levinas, a ética contemporânea se estabelece entre o indivíduo e o outro, na eminência do encontro face a face, e se constitui enquanto chamado proferido por esse outro: o "como agir" se transforma, portanto, em um "como agir" diante do e na direção do outro. Como consequência, a ação na direção do outro envolve presença, testemunho que implica participação, e, consequentemente, responsabilidade pelo outro quando a condição dele depende da minha ação - como em Room 40. No evento performativo, estar presente, testemunhar e participar da constituição e desenrolar do evento compreenderia o seguinte: 
To be there is, first, simply to be present, to attend, as at the theatre; to be there is, second, to be part of it, to participate, as in politics, for example; and finally, to be there is to be there for someone, to engage in a responsibility of care or support, to accept an ethical responsibility for the other. (RIDOUT, 2009, p. 64)

Esse processo de testemunho de uma cena que nos aponta precisamente à nossa responsabilidade diante do outro é vivenciado enquanto momento de extremo desconforto, pois de espectadores invisíveis na plateia nos tornamos constituintes e atuantes em um contexto no qual somos afetados ao mesmo tempo que afetamos e através do qual exercemos nossa crueldade. E nessa afetação nossa presença é intensificada, e nossa corporeidade espectatorial delatada ao contexto: já não somos mais invisíveis como nos percebíamos, nos tornamos visíveis, sobretudo, para nós mesmos, espectadores das nossas ações e reações. Segundo Drew Leder, em The absent body (1990), o homem tem uma relação um tanto paradoxal com o seu corpo e, mesmo que a sua vivência seja incorporada, a experiência cotidiana do corpo é caracterizada enquanto ausência, uma vez que na nossa experiência diária nosso foco geralmente se situa sobre objetos externos a nós mesmos, exteriores aos confins dos nossos corpos. No entanto, a situação é revertida quando diante de uma disfunção, ou situação desconfortável, o corpo retorna a nossa atenção e se firma enquanto presença intensificada que confronta a nossa ideia de ser (LEDER, 1990, p. 4); ou seja, enquanto questionamento da nossa identidade. Um dos momentos nos quais a presença do nosso corpo retorna intensificada a nós mesmos, invadindo-nos, é, segundo o autor, quando nos confrontamos com o outro, uma vez que: " $M y$ awareness of my body is a profound social thing, arising out of experiences of the corporeality of other people and of their gaze directed back on me". (Ibid., p. 92)

Em conclusão, esse campo potencial da ação e da experiência da responsabilidade pelo outro, sentida na carne, reside precisamente no momento do encontro com o outro, e se instaura enquanto afeto que transtorna e revela a perturbação contida nas estruturas de convívio no contexto do evento performativo. Nesse processo, o espectador pode facilmente não se identificar com a sua visão sobre si mesmo, pois é impelido à ação sem tempo para garantir a consonância entre esta e sua ideia de ética pessoal. Essa circuns- 
tância instaura um processo liminar, em que a identidade é desestabilizada e o testemunho revela a problematização da relação performativa. Porque na inabilidade de nos movermos pelo outro existe o horror, na nossa ética frouxa, cheia de concessões feitas diariamente, existem espaços vazios e ambivalentes que nos delatam a nós mesmos. É nesse horror do abandono e do costume diante da dor do outro, em que reside o preciso momento da percepção do choque possível de ser veiculado pela cena: o choque percebido pelo desvelamento de questões diversas encobertas por estruturas diárias, mas reveladas pelas intensificações instauradas pela cena. É, portanto, no momento da chamada à ação participativa em uma estrutura expressiva, a cena, que questiona a ética perante o outro, que a crueldade e aceitação da violência do testemunhador se intensificam: ali a responsabilidade diante do outro se torna evidente, e a ação transformadora é sugerida pela experiência de limites éticos.

\section{Referências bibliográficas}

BISHOP, C. Artificial hells: Participation arts and the politics of spectatorship. Londres: Verso, 2012.

BONFITTO, M. Entre o ator e o performer: Alteridades, presenças, ambivalências. São Paulo: Perspectiva, 2013.

DEBORD, G. Society of the spectacle. Eastbourne, Inglaterra: Soul Bay, 2009.

ETCHELLS, T. On risk and investment. In: Certain fragments: Contemporary performance and forced entertainment. Londres; Nova York: Routledge, 1999. GREHAN, H. Performance, ethics and spectatorship in a global age. Basingstoke, Reino Unido: Palgrave Macmillan, 2009.

LEDER, D. The absent body. Chicago; Londres: The University of Chicago, 1990.

RANCIÈRE, J. O espectador emancipado. Lisboa: Orfeu Negro, 2010.

RIDOUT, N. Theatre \& ethics. Basingstoke: Palgrave Macmillan, 2009.

STODDARD, C. Towards a phenomenology of the witness to pain: Dis/identification and the orlanian other. Performance Paradigm, n. 5.1, May 2009. Disponível em: <http://www.performanceparadigm.net/index.php/journal/article/view/65>. Acesso em: 31 jan. 2016.

Recebido em 31/03/2016

Aprovado em 03/05/2016

Publicado em 30/06/2016 